\title{
The legal position of delivering dental care in a time of COVID-19
}

\section{Chris Deery' ${ }^{1}$}

\section{A commentary on}

\section{Elzein R, Bader B, Rammal A et al.}

Legal liability facing COVID-19 in dentistry: Between malpractice and preventive recommendations. J Forensic Leg Med 2021; 78: 102123.

\section{Abstract}

Aim To provide an international perspective on COVID-19 (SARSCoV-2) safety measures and discuss the medico-legal perspective of providing dental care during the COVID-19 pandemic.

Data sources This paper is a narrative review. The authors are drawn from academic dentistry and academic law.

COVID-19 safety measures in dental clinics Dental care professionals are considered to be at high risk of exposure and subsequent transmission of COVID-19. Therefore, it is of great importance that dental professions put in place measures to prevent cross infection from the virus. These measures include screening patients and spacing of appointments to allow fallow time. Within the clinic, there is a requirement for adequate ventilation (perhaps aided by air cleaners and disinfection air fogging devices) together with cleaning and use of alcohol gels to ensure hands are clean. With regards to dental treatment, the measures expected are also itemised, such as the use of virucidal antiseptic mouthwash, use of personal protective equipment, rubber dam and moving to non-aerosol generating procedures wherever possible. COVID-19 safety measures and the law The point is made that the need for the implementation of these precautions is not only necessary for cross-infection prevention but also for the avoidance of legal issues. The paper discusses the liability of a dentist, both criminal and civil, should a person contract COVID-19 as a result of attending for dental treatment. Although opinion varies across legal jurisdictions, the general consensus is that a practitioner would only be liable if they had been negligent. This is not just the case when guidelines are available, whether legally enforced or not, as the practitioner is required to deliver care in an up-to-date and evidence-based manner. There is a need to document persuasions taken to protect the practitioner from litigation. Conclusion Dentists should follow the scientific evidence to reduce as much as possible the risk of them contracting or spreading COVID-19. In addition, to avoid criminal or civil legal consequences, all procedures to avoid cross infection should be documented, as in not doing so, the practitioner will not be able to prove they were carried out.

\section{Commentary}

This paper aims to give an international perspective on COVID-19 cross-infection measures and the legal (both criminal and civil) position practitioners could find themselves in should a patient contract COVID-19 as a result of attending for care. The authors

\section{GRADE rating}

\section{Practice points}

- Have standard operating procedures in place to demonstrate adherence to evidenced cross-infection prevention.

- Document the steps taken to prevent cross infection. use a narrative review to present and discuss this information. It could be argued that a more structured approach, such as a scoping review or systematic review, would have been more appropriate for the first element of the paper, which looks at the procedures that can be put in place to reduce or prevent the risk to the practitioner, their clinic staff and patients of contracting COVID-19. This list does seem comprehensive and the authors do recognise that the evidence for some of the potential procedures is not strong.

The second section on the legal aspects does lend itself to a narrative approach, but it is very ambitious. The aim is to provide an international perspective but only the laws in four countries are actually presented as examples (France, Lebanon, UK and US). The conclusion of the review of the legal position is that a dentist has a duty to be up to date and to practise based on the best evidence. The consensus of the legal opinion presented is that a dentist would be liable if negligence could be demonstrated. Assuming that very few dentists are negligent, in order to protect themselves from legal action, it is vital that the procedures followed to protect the patient, staff and themselves should be documented. In my own view, the simplest and most effective way to achieve this is to use standard operating procedures based on the best evidence and preferably national guidelines. Of course, staff also have to ensure all staff are adequately trained in their application. If this approach is adopted, the dentist only needs to record deviations from the standard operating procedures and the reason for this deviation.

This paper has an error; it states that the first lockdown commenced in the UK with an associated suspension of routine dental care in January 2020 - this is not the case; lockdown commenced in the UK in March 2020. A further issue is that even at the time of publishing, this paper was out of date. As yet, this statement on page 3 is not true: '[...] life gradually returning to normal [...]', as we see third waves of COVID19 across the world. Although the authors are correct that there is a real potential for COVID-19 to be transmitted to dental practitioners, clinic staff and patients, as far as I am aware, the procedures put in place to minimise this risk are proving effective. Sadly, as with many papers published on the back of the COVID-19 pandemic, I do not feel this paper adds anything to what we knew already.

\section{Author affiliation}

${ }^{1}$ Dean, Professor/Honorary Consultant in Paediatric Dentistry, School of Clinical Dentistry, University of Sheffield, Claremont Crescent, Sheffield, S10 2TA, UK. Correspondence to: Chris Deery Evidence-Based Dentistry (2021) 22, 84.

https://doi.org/ 10.1038/s41432-021-0180-4 